\title{
Developmental Dysplasia of the Hip
}

\section{Open Reduction as a Risk Factor for Substantial Osteonecrosis}

\author{
G. B. Firth MBBCh, FCS (Orth) (SA), MMed (Orth) (Wits), \\ A. J. F. Robertson MBBCh, MMed (Orth) (Wits), \\ A. Schepers MBBCh, FRCS (Ed), L. Fatti PhD
}

Received: 18 August 2009/Accepted: 11 May 2010/Published online: 8 June 2010

(C) The Association of Bone and Joint Surgeons (B) 2010

\begin{abstract}
Background Kalamchi and MacEwen (K\&M) described a four-group scheme for classifying osteonecrosis (ON) following treatment for developmental dysplasia of the hip (DDH). However, the four groups can overlap in radiographic appearance, making assessment difficult.

Questions/purposes We (1) describe a simplified K\&M classification; (2) determined whether the simplified classification was reliable; and (3) assessed whether differences in the type of reduction or age at reduction resulted in different degrees of $\mathrm{ON}$.

Patients and Methods We retrospectively reviewed 300 patients with DDH treated with either open or closed reduction. We included 101 of these patients (133 involved hips). Intraobserver and interobserver reliability testing of the original and our simplified classification was performed. ON occurred in 64 hips (48\%). Of these, 22 had original K\&M Group I disease (classified as simplified
\end{abstract}

Each author certifies that he or she has no commercial associations (eg, consultancies, stock ownership, equity interest, patent/licensing arrangements, etc) that might pose a conflict of interest in connection with the submitted article.

Each author certifies that his or her institution approved the human protocol for this investigation, that all investigations were conducted in conformity with ethical principles of research, and that informed consent for participation in the study was obtained.

G. B. Firth $(\bowtie)$, A. J. F. Robertson, A. Schepers

Department of Orthopaedic Surgery, Room 4M12, University of the Witwatersrand Medical School, 7 York Road, Parktown, Johannesburg 2193, South Africa

e-mail: greg.firth@gmail.com

L. Fatti

School of Statistics and Actuarial Science, University of the Witwatersrand, Johannesburg, South Africa
Group A), and 42 had original K\&M Groups II, III, or IV disease (classified as simplified Group B). The mean age of the patients at final followup was 12.4 years (range, 626.3 years).

Results The interobserver reliability of the simplified classification was greater than that of the K\&M classification ( 0.51 vs 0.33 , respectively). Closed reduction after skin traction resulted in a lower incidence of Group B ON than open reduction, regardless of age at reduction.

Conclusions We propose a simplified and more reliable classification of ON after DDH. With the new classification we found type of reduction (closed with traction versus open without femoral shortening) but not age influenced the risk of ON.

Level of Evidence Level IV, therapeutic study. See Guidelines for Authors for a complete description of levels of evidence.

\section{Introduction}

The development of $\mathrm{ON}$ of the femoral head is a serious complication from treatment of DDH [7, 12, 24, 25]. In 1969, Salter et al. [21] described two types of ON. The first group had temporary irregular ossification which was not considered true $\mathrm{ON}$ and the second group included all other degrees of ON. Others $[4,9]$ have classified $\mathrm{ON}$ as either partial or complete involvement of the femoral head, with specific vascular occlusions resulting in distinctive morphologic patterns. In 1980, Kalamchi and MacEwen [12] described a four-group classification of $\mathrm{ON}$ as a complication of treatment. Group I disease (Fig. 1) results in a partial vascular insult and temporary changes to the femoral head with complete resolution and no long-term illeffects. In Groups II, III, and IV (Figs. 2-4), there is 
Fig. 1A-B Radiographs taken at (A) 13 months and (B) 7 years show Group A ON (original K\&M Group I).
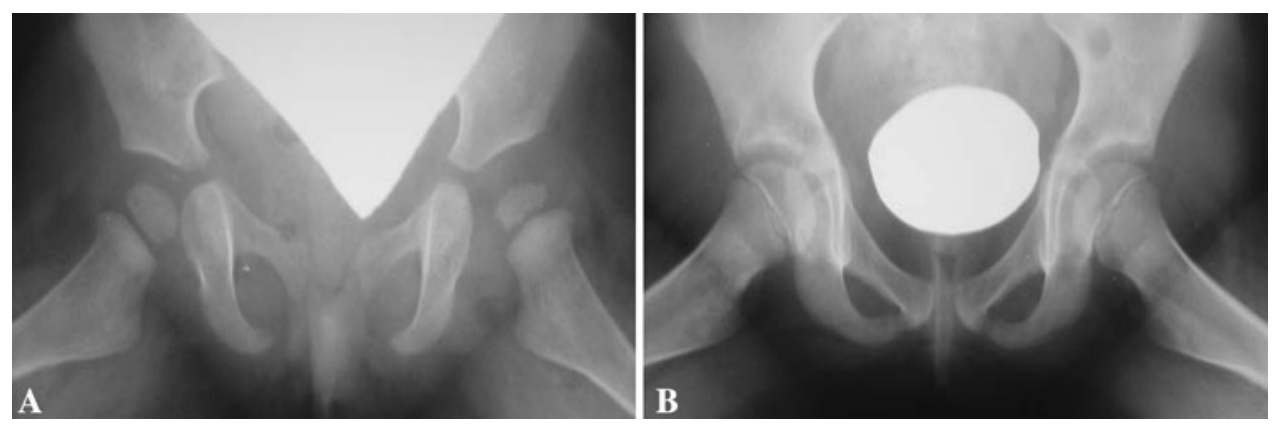

Fig. 2A-B Radiographs taken at (A) 40 months and (B) 22 years show Group B ON (original K\&M Group II).
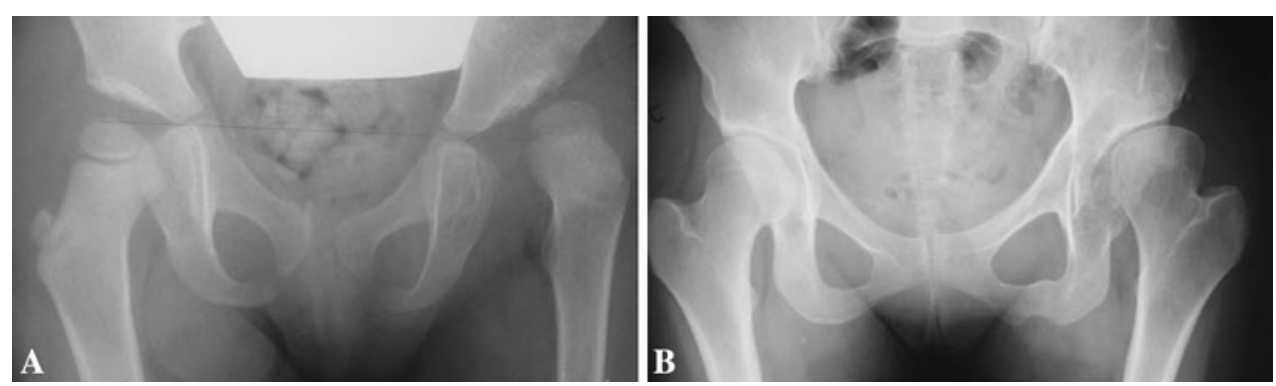

Fig. 3A-B Radiographs taken at (A) 41 months and (B) 9.75 years show Group B ON (original K\&M Group III).

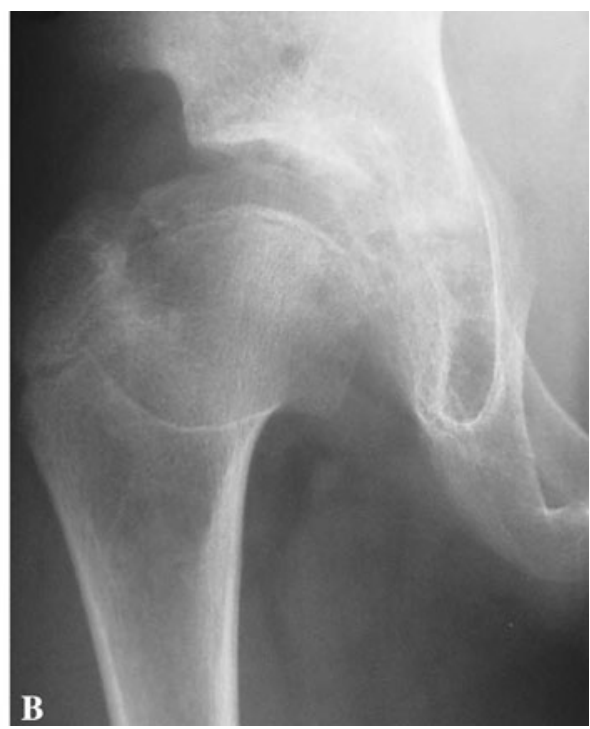

additional damage to the growth plate resulting in coxa valga, coxa breva, or complete femoral head destruction respectively. Patients with Group II disease will have a minimal leg length discrepancy and early degenerative osteoarthritis. Patients with Group III disease have functional coxa vara, abductor weakness, and a resultant limp. They also are at risk of having early osteoarthritis develop. Patients with Group IV disease will have a leg length discrepancy, hip degeneration, early osteoarthritis, and limitation in range of movement [12]. In 1991, Keret and MacEwen [13] modified the Salter classification by dividing $\mathrm{ON}$ into mild, moderate, or severe. They described mild ON (29 hips) as having either temporary irregular ossification of the ossific nucleus or unresolved medial flattening of the femoral head with ultimate resolution of head sphericity. Moderate ON (17 hips) was described as failure of the ossific nucleus to ossify in a specific area with potential to lead to lateral tilt. Severe ON (44 hips) included those whose ossific nucleus failed to appear 1 year after reduction, and when it did appear, it was flattened, irregular, and dense. They found moderate or severe persistent medial bowing of the proximal femur occurred in $44 \%$ of hips with severe ON.

These classifications are complex and grouping can be open to interobserver interpretation with overlap between groups. None of these classifications have undergone reliability testing. Further, the four groups of the original $\mathrm{K} \& \mathrm{M}$ classification frequently can overlap in radiographic 


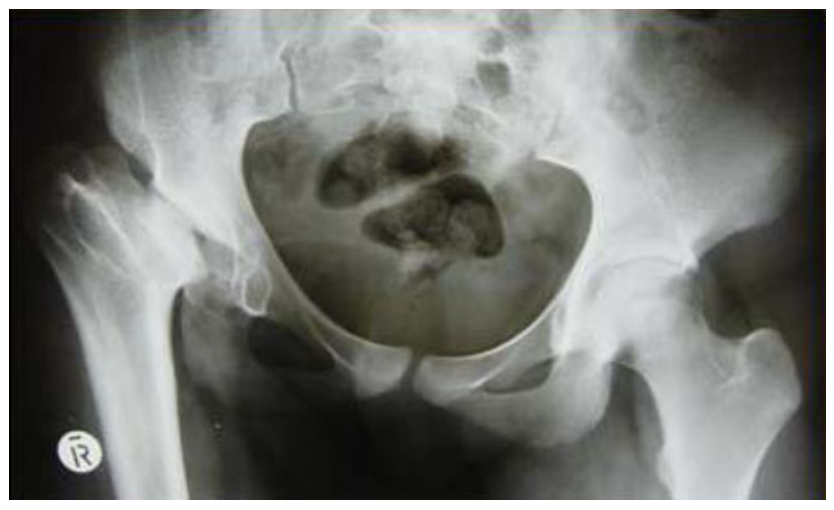

Fig. 4 A radiograph taken at 16.5 years shows Group B ON (original K\&M Group IV).

appearance and be difficult to differentiate from one another. For example, a Group II (coxa valga) hip also may have a coxa magna, and a Group III (coxa breva) hip may be associated with a completely destroyed femoral capital epiphysis (Group IV).

The methods of treating DDH have evolved during the last 50 years to minimize the incidence of ON $[6,7,11,14$, $15,17-19,23,24]$. Some authors advocate prolonged prereduction traction and closed reduction even in children up to 5 years of age $[15,18,19]$ with rates of ON ranging between $2 \%$ to $60 \%$. Some advocate open reduction with femoral shortening and pelvic osteotomy in children older than 12 to 18 months $[7,11,17]$ with rates of ON ranging between $8 \%$ to $31 \%$.

We (1) describe a simplified $\mathrm{K} \& \mathrm{M}$ classification to better assess the impact of reduction type and age at reduction on the grade of osteonecrosis; (2) determined whether the simplified classification was reliable; and (3) determined whether differences in the type of reduction (open versus closed) or age at reduction resulted in different degrees of ON.

\section{Patients and Methods}

We retrospectively reviewed the charts and radiographs of 300 patients with DDH, treated by a standard protocol between 1978 and 2004. All hips that underwent closed or open reduction for DDH were included. The group of ON, age at presentation, age at final followup, and details of treatment were recorded. We excluded 199 patients: 80 patients treated successfully with the Pavlik harness, 98 patients younger than 6 years at final followup, 12 lost to followup owing to inadequate record keeping, and nine with teratologic dislocation. The age of 6 years was deemed the minimum to adequately assess the degree of ON affecting the femoral head, in particular the effect of partial damage to the growth plate in an attempt to properly grade the hip according to the original $\mathrm{K} \& \mathrm{M}$ classification $[3,12,13,27]$. This left a final population of 101 patients with 133 involved hips. There were 94 girls and seven boys in the final population group. Thirty-two patients had bilateral DDH. Of the 133 hips, ON developed in 64 (48\%): 22 hips (34\%) were Group A and 42 hips (66\%) were Group B. Of the Group B hips, 10 were original K\&M Group II, one was Group III, and 31 were Group IV (Fig. 5). Seventy-seven hips had a closed reduction and 56
Fig. 5 A flowchart shows the distribution of ON among the 133 hips according to the original and our simplified $K \& M$ classifications.

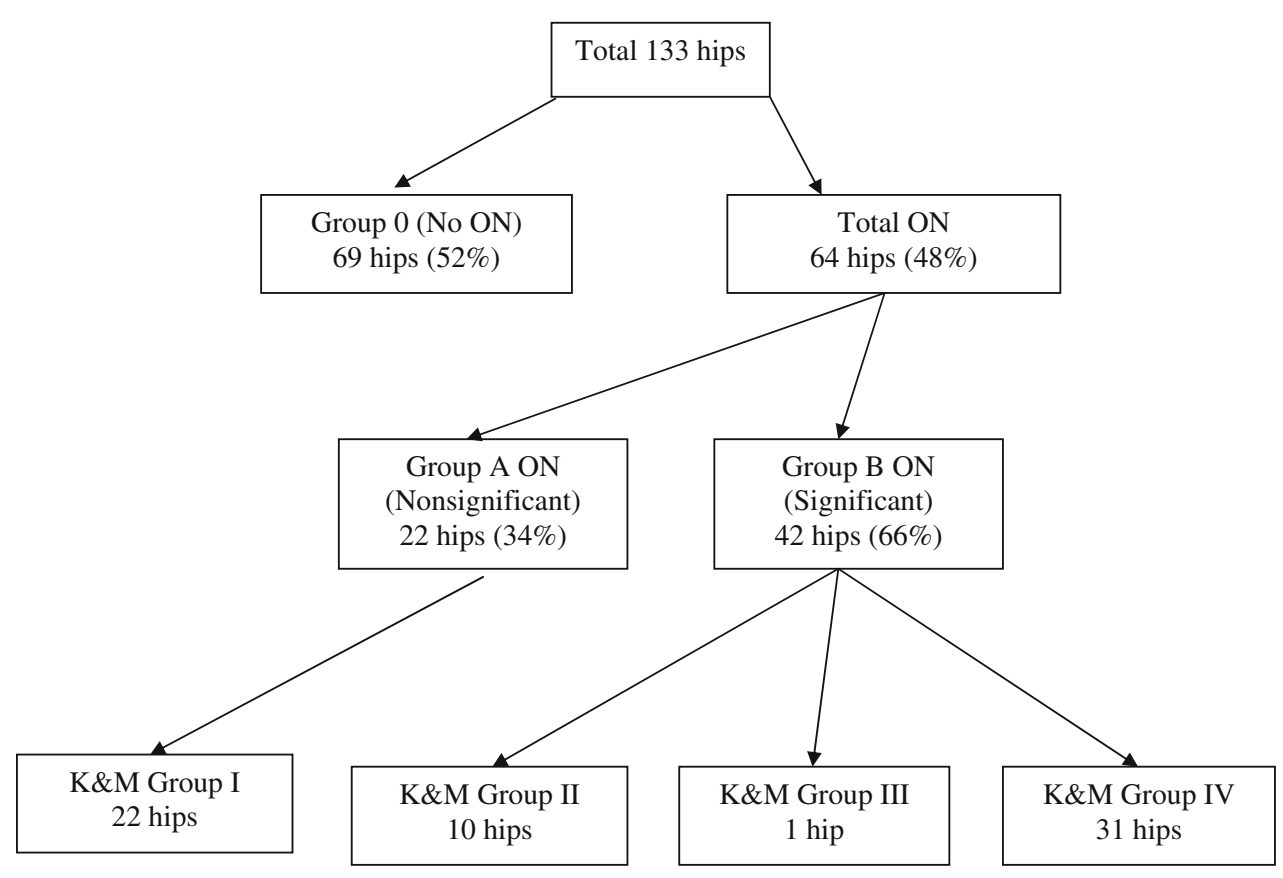


hips an open reduction. The mean age of the patients was 15 months (range, 2-65 months) for closed reduction and 24 months (range, 6-117 months) for open reduction. The mean age of the patients at final followup was 12.4 years (range, 6-26.3 years). Minimum followup was 4 years (mean, 10.8 years; range, 4-26.3 years). Approval from the University of Witwatersrand Ethics Committee was obtained.

All patients were treated by one surgeon (AS) using one protocol. Prereduction skin traction was applied using Gallows' traction. The child was suspended with the buttocks just off the bed. No additional weights were used. Five children (six hips) between 54 months and 117 months did not receive prereduction traction. The children were placed in traction and progressively abducted, until they reached $45^{\circ}$ abduction. This took an average of 10 days (range, 5-21 days). The angle was measured between a vertical line drawn between the abducted leg (perpendicular to the pelvis) and the affected leg, with the observer ensuring that the pelvis was as horizontal as possible. With the patient under general anesthesia, a closed reduction was performed; no forced reduction was attempted. Percutaneous adductor tenotomy was performed if hip abduction was limited to $45^{\circ}$ in the operating room. The procedure was performed to maximize abduction and increase the safe zone. Nine hips had an adductor tenotomy. A closed reduction was deemed successful if the hip remained reduced in the safe zone. On radiographs, Shenton's line had to be intact or a line drawn up the femoral shaft had to intersect the triradiate cartilage. An arthrogram was not performed.

If a closed reduction was not possible, an open reduction was performed. Open reduction was performed via an anterior approach to the hip as described by Canale and Beaty after Somerville [5]. The psoas tenotomy was performed as the tendon crossed the hip capsule. We performed no femoral shortenings or pelvic osteotomies simultaneously at the time of open reduction.
After reduction (whether closed or open), the hip was immobilized in a plaster of Paris spica cast for 3 months with a cast change at 6 weeks. All hips were placed in $90^{\circ}$ flexion, in the safe zone (generally $45^{\circ}$ abduction) and in neutral rotation. On removal of the spica cast at 3 months, an abduction cast was applied for 6 to 12 weeks.

Radiographs were taken immediately postreduction in the operating room before waking the child. Clinical followup and radiographs then were performed at 6 weeks, 3 months, and 12 months. Followup was annual thereafter. After removal of the abduction cast, the patients were allowed to fully weightbear and mobilize as tolerated. No MRI or CT was performed to assess reduction or acetabular development. Most patients were treated in the 1980s and 1990s when these investigations were not in common use.

Three of us (GBF, AJFR, AS) assessed serial radiographs according to the K\&M classification. The intraobserver and interobserver reliability were recorded for the original and simplified $\mathrm{K} \& \mathrm{M}$ classification for each observer (GBF, AJFR, AS) using the weighted kappa test in 113 of the 133 involved hips. In the simplified K\&M classification, patients without ON were classified as Group 0 , the original $\mathrm{K} \& \mathrm{M}$ Group I was termed nonsignificant ON and classified as Group A (Fig. 1), and the original K\&M Groups II (Fig. 2), III (Fig. 3), and IV (Fig. 4) were termed significant ON and classified as Group B (Table 1).

We determined the intraobserver and interobserver reliability between the original and simplified $\mathrm{K} \& \mathrm{M}$ classifications using the weighted kappa coefficient. The weighted kappa takes into account how far apart the discrepancies in rating between observers are and is appropriate for ordinal rating scales. We determined differences in proportions of patients with $\mathrm{ON}$ who had closed and open reductions using the Pearson chi square test. We determined differences in degree of $\mathrm{ON}$ and age at reduction using the Kruskal-Wallis test. The degree of ON also was modeled using a proportional odds logistic regression with type of reduction and age at reduction as explanatory

Table 1. Differences between the original and simplified K\&M classifications

\begin{tabular}{lll}
\hline Simplified K\&M classification & Original K\&M & Final radiographic description \\
\hline $\begin{array}{l}\text { Group 0 } \\
\text { No ON }\end{array}$ & No ON & No signs of ON \\
Group A & Group I & $\begin{array}{c}\text { Changes affecting ossific nucleus but resulting in an essentially } \\
\text { normal head at final followup }\end{array}$ \\
$\begin{array}{l}\text { Nonsignificant ON } \\
\text { Group B }\end{array}$ & Group II & Lateral physeal damage resulting in coxa valga \\
Significant ON & Group III & Central physeal damage resulting in coxa breva \\
& Troup IV & $\begin{array}{c}\text { Total damage to head and physis resulting in deformity of femoral } \\
\text { head and neck }\end{array}$
\end{tabular}

$\mathrm{K} \& \mathrm{M}=$ Kalamchi and MacEwen classification; $\mathrm{ON}=$ osteonecrosis. 
variables. Statistical analysis was performed using $\mathrm{SAS}{ }^{\circledR}$ 9.1 (SAS Institute Inc, Cary, NC) and Stata ${ }^{\circledR}$ (StataCorp LP, College Station, TX) programs.

\section{Results}

Although the observed proportion of agreement increased for each of the observers comparing the original and the simplified classifications, the intraobserver reliability did not consistently increase (Table 2). The interobserver reliability for all three observers (GBF, AJFR, AS) in 113 hips gave weighted kappa values of 0.33 using the original $\mathrm{K} \& \mathrm{M}$ classification and 0.51 using the simplified $\mathrm{K} \& \mathrm{M}$ classification. The proportions of Group 0, and Groups A and $\mathrm{B}$ ON differed between patients who had closed reduction and open reduction. The majority of patients without ON (Group 0) (65\%) had been treated with closed reduction whereas the majority $(57 \%)$ of patients with Group B ON had been treated with open reduction $(\mathrm{p}<0.001)$ (Table 3). Age at reduction was similar $(\mathrm{p}=0.11)$ between patients with different degrees of $\mathrm{ON}$ (Table 4).

Type of reduction $(\mathrm{p}<0.001)$, but not age $(\mathrm{p}=0.25)$ influenced the likelihood of $\mathrm{ON}$.

\section{Discussion}

$\mathrm{ON}$ is a complication of DDH that often results in a poor long-term outcome. Attempts must be made to prevent subluxation of the femoral head associated with $\mathrm{ON}$ to improve the long-term clinical outcome [7, 12, 24, 25]. The published rates of ON vary widely; the rate is dependent on the evaluator's stringency of inclusion, method of evaluation, and age of the patient at final followup. Malvitz and Weinstein [18] reported a rate of ON of $60 \%$ in a group of 152 patients treated at a mean age of 21 months with closed reduction. In a group of 210 patients treated at a mean age of 14 months with closed reduction, Brougham et al. [3] reported a rate of $\mathrm{ON}$ of $47 \%$. The current reported rate of $48 \%$ is thus the second highest rate of $\mathrm{ON}$ reported as a complication of the treatment of DDH (Table 5). Other studies have found a lower incidence of ON $[1,2,7,8,11,12,15-17,19,22,23,26,27]$, which may be related to the stringency of inclusion or the type of treatment performed (Table 5). All hips with any change to the femoral head were included in our study as having ON. Open reduction via a medial approach resulted in a $20 \%$ to $27 \%$ incidence of ON $[1,11]$. Studies using open reduction combined with femoral derotation and shortening resulted in an $8 \%$ to $36 \%$ incidence of ON $[7,8,26]$ (Table 5). The

Table 2. Intraobserver reliability for the original and simplified $K \& M$ classifications

\begin{tabular}{lllll}
\hline Observer & \multicolumn{2}{l}{ Original K\&M classification } & & \multicolumn{2}{l}{ Simplified K\&M classification } \\
\cline { 2 - 3 } & $\begin{array}{l}\text { Observed proportion } \\
\text { of agreement }\end{array}$ & Weighted kappa & & $\begin{array}{l}\text { Observed proportion } \\
\text { of agreement }\end{array}$ \\
\hline GBF & $84 \%$ & 0.59 & $90 \%$ & 0.66 \\
AJFR & $84 \%$ & 0.54 & $87 \%$ & 0.52 \\
AS & $89 \%$ & 0.64 & $91 \%$ & 0.59 \\
\hline
\end{tabular}

Table 3. Relationship between type of reduction and ON

\begin{tabular}{llcr}
\hline Type of reduction & Group 0 (69 hips) & Group A (23 hips) & Group B (41 hips) \\
\hline Closed reduction (77 hips) & $50(65 \%)$ & $18(23 \%)$ & $9(12 \%)$ \\
Open reduction (56 hips) & $19(34 \%)$ & $5(9 \%)$ & $32(57 \%)$ \\
\hline
\end{tabular}

$\mathrm{p}<0.001$ using Pearson chi square test; $\mathrm{ON}=$ osteonecrosis.

Table 4. Age at reduction and final followup in relation to grade of ON

\begin{tabular}{llll}
\hline Age & Group 0 (69 hips) & Group A (23 hips) & Group B (41 hips) \\
\hline Age at reduction (months) & $18.8(2-65)$ & $13.6(2-27)$ & $21.2(6-117)$ \\
Age at final followup (years) & $11.0(6-20.4)$ & $13.4(6.3-24)$ & $14.3(6-26.3)$
\end{tabular}

Values are expressed as mean, with range in parentheses; $\mathrm{p}=0.11$ using Kruskal-Wallis test. ON $=$ osteonecrosis. 


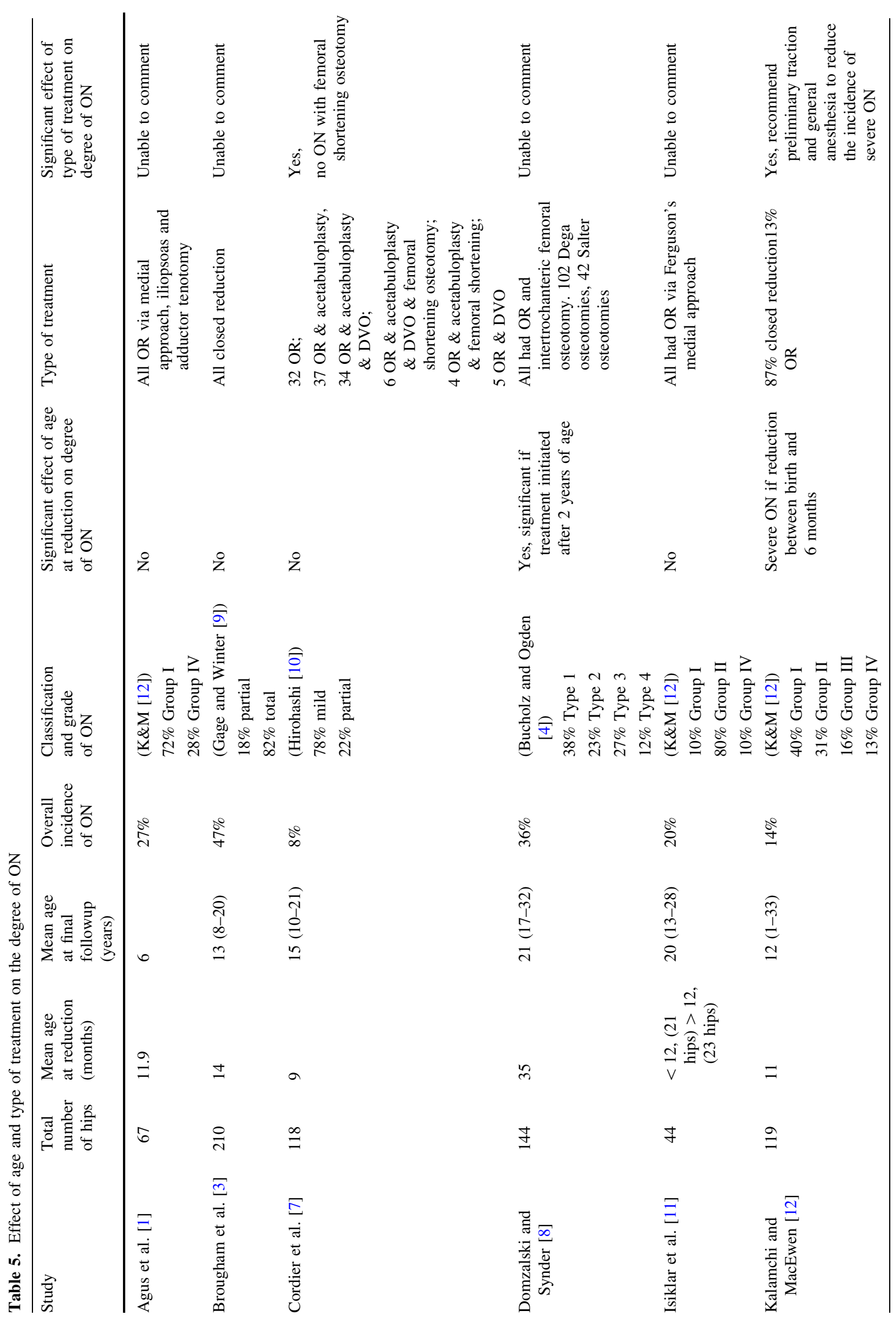




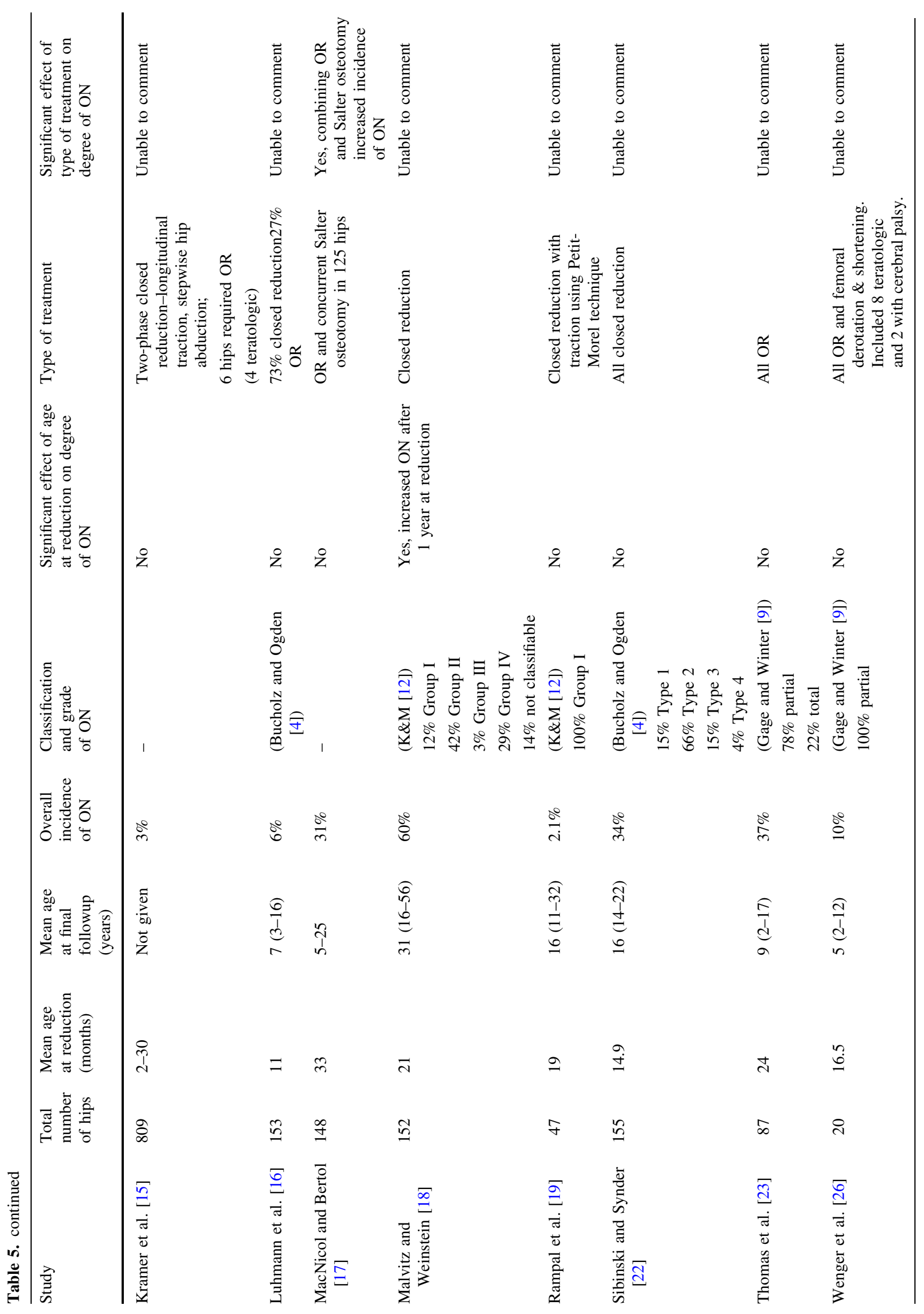


existing classifications for $\mathrm{ON}$ are complex and grouping can be open to interpretation with overlap between groups. None of these classifications have undergone reliability testing. The four groups of the original K\&M classification frequently can overlap in radiographic appearance and be difficult to differentiate from one another. For example, a Group II (coxa valga) hip also may have a coxa magna, and a Group III (coxa breva) hip may be associated with a completely destroyed femoral capital epiphysis (Group IV). We (1) describe a simplified $\mathrm{K} \& \mathrm{M}$ classification to better assess the impact of reduction type and age at reduction on the grade of $\mathrm{ON}$; (2) determined whether the simplified classification was reliable; and (3) assessed whether differences in the type of reduction (open versus closed) or age at reduction resulted in different degrees of $\mathrm{ON}$.

We note three major study limitations. First, the study was retrospective and a large number of patients were excluded. We excluded 199 patients from the original group of 300: 80 patients were treated successfully with the Pavlik harness, 98 were younger than 6 years at final followup, 12 were lost to followup owing to inadequate record keeping, and nine were teratologic. Second, although open reduction is an independent risk factor for Group B ON, this may be alleviated by femoral shortening. Group B ON may be an indication of the more severe hip in which all other treatments have failed, and not caused by the open reduction. Third, we found no published studies validating the intraobserver and interobserver reliability of the original K\&M classification, and therefore had no benchmark with which to compare the findings of our simplified K\&M classification. We therefore performed our own intraobserver and interobserver reliability testing using the weighted kappa coefficient for both classifications.

Our main purpose was to present a simplification of the original $\mathrm{K} \& \mathrm{M}$ classification by dividing it into Group 0 (no ON), Group A (original Group I), and Group B (original Groups II-IV). The simplified K\&M classification is less ambiguous. It is easier to remember and can be used more easily in the outpatient department. Groups II, III, and IV all result in varying degrees of leg length discrepancy, Trendelenburg gait, and subsequent risk of early osteoarthritis [12]. In the original and simplified classifications, the kappa value was greater than 0 , indicating agreement was beyond that expected by chance alone. The simplified classification has intraobserver reliability that is equal to that of the original classification (Table 2) and improved interobserver reliability (kappa $=0.51$ vs 0.33 ).

We found open reduction without femoral shortening was associated with an increased severity of ON. Kramer et al. [15], Rampal et al. [19] and Zionts and MacEwen [27] showed closed reduction, where possible, had fewer 
complications, even in the slightly older patient (1-5 years) (Table 5). Cordier et al. [7] reported an incidence of $8 \%$ ON in 118 hips using open reduction and a combination of acetabuloplasty, femoral shortening, and derotation. Domzalski and Synder [8] found that open reduction with a concurrent acetabular procedure and an intertrochanteric femoral osteotomy resulted in a $36 \%$ incidence of $\mathrm{ON}$ in 144 hips. Thomas et al. [23] concluded that open reduction did not affect the degree of ON. Their series of 24 hips resulted in a $37 \%$ incidence of ON. Wenger et al. [26] suggested performing an open reduction and femoral shortening osteotomy at a younger age in special circumstances to reduce the pressure on the femoral head in younger patients. Their series of 20 hips resulted in a $10 \%$ incidence of ON. As a result, we now perform a femoral shortening osteotomy if an open reduction is required to reduce pressure on the femoral head and subsequent risk of ON (Table 5).

We observed age at reduction had no effect on the incidence or degree of ON. A recent meta-analysis on the subject [20] also reported the presence of the ossific nucleus after reduction had no effect on the outcome of ON. Luhmann et al. [16] showed that early reduction (before the appearance of the ossific nucleus) halved the need for a secondary procedure with no statistically significant increase in ON.

The original K\&M classification for $\mathrm{ON}$ has been simplified with improved interobserver reliability. In this series, open reduction without concurrent femoral shortening osteotomy resulted in a greater incidence of Group B ON compared with hips undergoing successful closed reduction at any age.

Acknowledgments We thank Nick Barrowman and Locardia Kuwanda for assistance with the statistical analysis.

\section{References}

1. Agus H, Omeroglu H, Ucar H, Bicimoglu A, Turmer Y. Evaluation of the risk factors of avascular necrosis of the femoral head in developmental dysplasia of the hip in infants younger than 18 months of age. J Pediatr Orthop B. 2002;11:41-46.

2. Albinana J, Dolan LA, Spratt KF, Morcuende J, Meyer MD, Weinstein SL. Acetabular dysplasia after treatment for developmental dysplasia of the hip: implications for secondary procedures. J Bone Joint Surg Br. 2004;86:876-886.

3. Brougham DI, Broughton NS, Cole WG, Menelaus MB. Avascular necrosis following closed reduction of congenital dislocation of the hip: review of influencing factors and long-term follow-up. J Bone Joint Surg Br. 1990;72:557-562.

4. Bucholz RW, Ogden JA. Patterns of ischaemic necrosis of the proximal femur in nonoperatively treated congenital hip disease. The Hip: Proceedings of the Sixth Open Scientific Meeting of the Hip Society. St Louis, MO: CV Mosby Co; 1978:43-63.

5. Canale ST, Beaty J. Campbell's Operative Orthopaedics. Ed 10. St Louis, MO: CV Mosby Co; 2007:1089-1091.
6. Cooperman DR, Wallensten R, Stulberg SD. Post-reduction avascular necrosis in congenital dislocation of the hip. $J$ Bone Joint Surg Am. 1980;62:247-258.

7. Cordier W, Tönnis D, Kalchschmidt K, Storch KJ, Katthagen BD. Long-term results after open reduction of developmental hip dislocation by an anterior approach lateral and medial of the iliopsoas muscle. J Pediatr Orthop B. 2005;14:79-87.

8. Domzalski M, Synder M. Avascular necrosis after surgical treatment for developmental dysplasia of the hip. Int Orthop. 2004;28:65-68.

9. Gage JR, Winter RB. Avascular necrosis of the capital femoral epiphysis as a complication of closed reduction of congenital dislocation of the hip: a critical review of twenty years' experience at Gillette Children's Hospital. J Bone Joint Surg Am. 1972;54:373-388.

10. Hirohashi K, Kambara T, Narushima M, Lee Y, Shimazu A. A radiographic study of ischemic necrosis following the treatment of CDH. J Jpn Orthop Assoc. 1982;56:927-928.

11. Isiklar ZU, Kandemir U, Ucar DH, Tumer Y. Is concomitant bone surgery necessary at the time of open reduction in developmental dislocation of the hip in children 12-18 months old? Comparison of open reduction in patients younger than 12 months old and those 12-18 months old. J Pediatr Orthop B. 2006;15:23-27.

12. Kalamchi A, MacEwen GD. Avascular necrosis following treatment of congenital dislocation of the hip. J Bone Joint Surg Am. 1980;62:876-888.

13. Keret D, MacEwen GD. Growth disturbance of the proximal part of the femur after treatment for congenital dislocation of the hip. J Bone Joint Surg Am. 1991;73:410-423.

14. Kim HW, Morcuende JA, Dolan LA, Weinstein SL. Acetabular development in developmental dysplasia of the hip complicated by lateral growth disturbance of the capital femoral epiphysis. J Bone Joint Surg Am. 2000;82:1692-1700.

15. Kramer J, Schleberger R, Steffen R. Closed reduction by two-phase skin traction and functional splinting in mitigated abduction for treatment of congenital dislocation of the hip. Clin Orthop Relat Res. 1990;258:27-32.

16. Luhmann SJ, Bassett GS, Gordon JE, Schootman M, Schoenecker PL. Reduction of a dislocation of the hip due to developmental dysplasia: implications for the need for future surgery. $J$ Bone Joint Surg Am. 2003;85:239-243.

17. Macnicol M, Bertol P. The Salter innominate osteotomy: should it be combined with concurrent open reduction? J Pediatr Orthop B. 2005; 14:415-421.

18. Malvitz TA, Weinstein SL. Closed reduction for congenital dysplasia of the hip: functional and radiographic results after an average of thirty years. J Bone Joint Surg Am. 1994;76:1777-1792.

19. Rampal V, Sabourin M, Erdeneshoo E, Koureas G, Seringe R, Wicart P. Closed reduction with traction for developmental dysplasia of the hip in children aged between one and five years. J Bone Joint Surg Br. 2008;90:858-863.

20. Roposch A, Stöhr KK, Dobson M. The effect of the femoral head ossific nucleus in the treatment of developmental dysplasia of the hip: a meta-analysis. J Bone Joint Surg Am. 2009;91:911-918.

21. Salter RB, Kostuik J, Dallas S. Avascular necrosis of the femoral head as a complication of treatment for congenital dislocation of the hip in young children: a clinical and experimental investigation. Can J Surg. 1969;12:44-61.

22. Sibinski M, Synder M. Lateral growth disturbances of the capital femoral epiphysis after nonoperative treatment of late developmental dislocation of the hip: thirty-five cases followed to skeletal maturity. J Pediatr Orthop. 2006;26:307-309.

23. Thomas IH, Dunin AJ, Cole WG, Menelaus MB. Avascular necrosis after open reduction for congenital dislocation of the hip: analysis of causative factors and natural history. $J$ Pediatr Orthop. 1989;9:525-531. 
24. Thomas SR, Wedge JH, Salter RB. Outcome at forty-five years after open reduction and innominate osteotomy for late-presenting developmental dislocation of the hip. J Bone Joint Surg Am. 2007;89:2341-2350.

25. Weinstein SL. Natural history of congenital hip dislocation (CDH) and hip dysplasia. Clin Orthop Relat Res. 1987;225: $62-76$.
26. Wenger DR, Lee CS, Kolman B. Derotational femoral shortening for developmental dislocation of the hip: special indications and results in the child younger than 2 years. $J$ Pediatr Orthop. 1995; 15:768-779.

27. Zionts LE, MacEwen GD. Treatment of congenital dislocation of the hip in children between the ages of one and three years. J Bone Joint Surg Am. 1986;68:829-846. 